\title{
Development of Propagation Path Loss Prediction Model for Mobile Communications Network Deployment in Osogbo, Nigeria
}

\author{
Hammed Lasisi, Yinusa A. Adediran, and Anjolaoluwa A. Ayodele
}

\begin{abstract}
Path loss, a major parameter in the analysis and design of the link budget of a telecommunication system, could be explained as the reduction in power density of an electromagnetic wave as it travels through space, over a distance. Path loss prediction models are therefore vital tools in cell planning, cell parameter estimation, frequency assignments and interference evaluation. This paper reports on the development of a path loss prediction model that describes the signal attenuation between transmitting and receiving antennas as a function of the propagation distance and other parameters for Osogbo, Nigeria. The model is extensively useful for conducting feasibility studies for signal prediction, coverage optimization and interference analysis during the initial phase of network planning in the study area and other areas with similar environmental and propagation characteristics.
\end{abstract}

Index Terms-Interference; Path Loss; Frequency Assignment; Cell Planning; Link Budget.

\section{INTRODUCTION}

In mobile communication, path loss models are necessary for proper planning, interference estimation, frequency assignments, and cell parameter estimation which are basic for network planning process as well as Location Based Service (LBS) techniques that are not based on Global Positioning System (GPS) system. Estimation of the path loss is usually termed prediction. Exact prediction is possible only for simpler cases, such as free space propagation or the flat earth model. For practical cases the path loss is calculated using a variety of approximations such as:

i. Empirical model: It is derived from in-depth field measurements, that is, measured and averaged losses along typical classes of radio links. It is efficient and simple to use. The most commonly used of this method are Okumura-Hata model, the COST Hata model and the Lee model.

ii. Deterministic model: This model is derived from and depend on the detailed and accurate description of all objects in the propagation space. This method is expected to produce more accurate and reliable prediction of the path loss than the empirical method; however, it is significantly more expensive in computational effort. Thus, it is used predominantly

Published on November 6, 2017.

H. Lasisi is a lecturer at Osun State University, Osogbo. He completed his BS, MS, and PhD Degree at University of Ilorin.

Y. A Adediran is a Professor at University of Ilorin in the Department of Electrical and Electronic Engineering.

A.A Ayodele is a first class graduate of Osun State University in Electrical and Electronic Engineering. for short propagation paths.

iii. Semi-deterministic model: This is based on both the empirical models and deterministic aspects [1].

\section{PATH LOSS MODELS}

Six path loss models are considered in the developmental process of the new model. They are: free space path loss model, Okumura-Hata model, COST 231 Hata model, Ericsson model, Egli model and the Lee model.

\section{A. Free Space Path Loss Model (FSPL)}

Free space path loss model is the simplest way to model path loss as all hindrances that might affect signal propagation are neglected. Path loss in free space defines how much strength of the signal is lost during propagation from transmitter to receiver across a free space devoid of vegetation. FSPL is dependent on frequency and distance, and is given as [2].

$P_{L_{F S L P}}=32.45+20 \log _{10} d+20 \log _{10} f$

where PLFSPL is free space path loss (in $\mathrm{dB}$ ), $\mathrm{f}$ is frequency $(\mathrm{MHz}), \mathrm{d}$ is distance between transmitter and receiver $(\mathrm{m})$.

\section{B. Okumura-Hata Model}

Okumura Hata model is based upon an extensive series of survey and measurements made in and around Tokyo city in 1968 between $150 \mathrm{MHz}$ and1500MHz. Depending on the area of interest, Okumura Hata path loss approximations could be stated as [3].

Urban area: $L(d B)=A+B \log _{10} R-E$

Suburban area: $L(d B)=A+B \log _{10} R-C$

Open area: $L(d B)=A+B \log _{10} R-D$

$A=69.5+26.16 \log _{10} f-13.82 \log _{10} H_{b}$

$B=44.9-6.55 \log _{10} H_{b}$

$C=2\left(\log _{10}\left(\frac{f}{28}\right)\right)^{2}$

$D=4.78\left(\log _{10} f\right)^{2}+18.33 \log _{10} f+40.94$

$E=3.2\left(\log _{10}\left(11.75 H_{m}\right)^{2}-4.97\right.$ for large cities $f>300 \mathrm{MHz}$

$E=8.29\left(\log _{10}\left(1.54 H_{m}\right)^{2}-1.1\right.$ for large cities $f<300 \mathrm{MHz}$

$E=\left(1.1 \log _{10} f-0.7\right) H_{m}-\left(1.56 \log _{10} f-0.8\right)$ for medium to small cities 
where $L(d B)$ is Path loss, $A, B, C, D$ and $E$ are the antenna correction facto. $R$ is the radial distance between the transmitter and the receiver. $H_{b}$ and $H_{m}$ are the base station antenna and mobile antenna heights respectively, and $f$ is the frequency of transmission $(\mathrm{MHz})$. The model is valid for the carrier frequency range $150 \mathrm{MHz} \leq f \leq 1500 \mathrm{MHz}$, base station height in the range $30 \mathrm{~m} \leq H_{b} \leq 200 \mathrm{~m}$, and mobile station height in the range $1 \mathrm{~m} \leq H_{m} \leq 10 \mathrm{~m}$ [3].

\section{COST 231-Hata Model}

Committee 231 of the European Cooperation in the field of Scientific and Technical Research (COST) in 1993 extended the Hata model frequencies of interest. The model, which was renamed COST 231-Hata model, is applicable in the frequency range of $500 \mathrm{MHz}$ to $2000 \mathrm{MHz}$ and can predict the median path loss for the distance of up to $20 \mathrm{~km}$ between the transmitter and the receiver with transmitter antenna height of $30 \mathrm{~m}$ to $200 \mathrm{~m}$, and receiver antenna height of $1 \mathrm{~m}$ to $10 \mathrm{~m}$ [5]. COST 231-Hata model can be used to calculate path loss in three different environments; urban, suburban and rural (flat) areas. It can be expressed as [6].

$$
\begin{aligned}
P_{L C M}=46.3+ & 33.9 \log _{10} f-13.84 \log _{10} H_{b}-a H_{m} \\
& +\left(44.9-6.55 \log _{10} H_{b}\right) \log _{10} d-C_{m}
\end{aligned}
$$

where $P_{L c m}$ is the path loss, $d$ is the distance between transmitting and receiving antennas $(\mathrm{km}), f$ is frequency $(\mathrm{MHz}), H_{b}$ is the transmitter antenna height $(\mathrm{m}), a H_{m}$ is the antenna height correction factor. The parameter $C_{m}$ has different values for different environments. It is given as $0 \mathrm{~dB}$ for rural as well as suburban and $3 \mathrm{~dB}$ for urban areas.

The parameter $a H_{m}$ (mobile antenna height correction factor) is defined in urban areas as

$a H_{m}=3.20 \log _{10}\left(11.75 H_{r}\right)^{2}-4.81$

The value for $\mathrm{aH}_{\mathrm{m}}$ in suburban and rural (flat) areas is given as

$a H_{m}=\left(1.11 \log _{10} f-0.7\right) H_{r}-\left(1.5 \log _{10} f-0.8\right)$

$H_{r}$ is the receiver antenna height in metres.

\section{Ericsson Model}

The Ericsson model software from Ericsson Company can be used to predict propagation path loss. Network planning engineers use it. This model also builds on the modified Okumura-Hata model to allow room for changes in parameters according to the propagation environment. Path loss according to this model is given as (Jalel etal., 2013)

$P_{L}=a_{0}+a_{1} \log _{10} d+a_{2} \log _{10} H_{b}+a_{3} \log _{10}\left(H_{b}+d\right)-$

$3.2\left(\log _{10}\left(11.78 H_{r}\right)\right)^{2}+g(f)$

$g(f)=44.49 \log _{10} f-4.78\left(\log _{10} f\right)^{2}$

where $P_{L}$ is the path loss, and $f$ is frequency $(\mathrm{MHz}), H_{b}$ is transmission antenna height $(\mathrm{m}), \mathrm{H}_{r}$ is receiver antenna height (m). The default values of these parameters $a_{0}, a_{1}, a_{2}$ and $a_{3}$ for different terrains are given in Table I.

TABLE I: VALUE OF $a_{0}, a_{1}, a_{2}$ AND $a_{3}$ PARAMETERS FOR ERICSSON MODEL

\begin{tabular}{ccccc}
\multicolumn{5}{c}{$[11]$} \\
\hline \hline Environment & $a_{0}$ & $a_{1}$ & $a_{2}$ & $a_{3}$ \\
\hline Urban & 36.20 & 30.20 & 12.00 & 0.1 \\
Suburban & 43.20 & 68.93 & 12.00 & 0.1 \\
Rural & 45.95 & 100.60 & 12.00 & 0.1 \\
\hline
\end{tabular}

\section{E. The Lee Model}

Reference [4] proposed this model in 1982. In a very short time it became widely popular among researchers and system engineers mainly because the parameters of the model can be easily adjusted to the local environment by additional field calibration. In the beginning, the Lee model was developed for use at $900 \mathrm{MHz}$ and has two modes: areato-area and point-to-point. Built as two different models, this model includes an adjustment factor that can be used to make the model more flexible to different regions of propagation. Lee model is given as [5].

Scenario 1:

Urban area, $P L=123.77+30.5 \log _{10} d+10 n \log _{10}\left(\frac{f}{900}\right)-$ $\alpha_{0}$

Scenario 2:

Surburban, $P L=99.86+38.4 \log _{10} d+10 n \log _{10}\left(\frac{f}{900}\right)-\alpha_{0}$

Scenario 3:

Rural area, $P L=86.12+43.5 \log _{10} d+$ $10 n \log _{10}\left(\frac{f}{900}\right)-\alpha_{0}$

Where $\alpha_{0}$ is the correction factor which accounts for the base station and mobile station antenna heights, transmit powers and antenna gain and it is given as

$\alpha_{0}=\alpha_{1}+\alpha_{2}+\alpha_{3}+\alpha_{4}+\alpha_{5}$

$\alpha_{1}=\left(\frac{h_{b}}{30.48}\right)^{2}$

$\alpha_{2}=\left(\frac{h_{m}}{3}\right)^{k}$

$\alpha_{3}=\left(\frac{P_{t}}{10}\right)^{2}$

$\alpha_{4}=\frac{G_{b}}{4}$

$\alpha_{5}=G_{m}$

$P_{L}$ is the path loss, $n$ is the path loss exponent chosen to be $3, f$ is frequency, $d$ is distance, $h_{b}$ is base station antenna height, $h_{m}$ is mobile station antenna height, $P_{t}$ is transmitter power, $G_{b}$ transmitter antenna gain, $G_{m}$ is mobile antenna gain. 


\section{F. Egli Model}

The Egli model is a terrain model for radio frequency propagation. It predicts the total path loss for point-to-point link (line of sight transmission). Typically, it is suitable for cellular communication scenarios where one antenna is fixed and another is mobile in the frequency range of $3 \mathrm{MHz}$ to $3 \mathrm{GHz}$ and where the transmission has to go over an irregular terrain. Egli model is expressed as [3].

$P L= \begin{cases}20 \log _{10} f+P_{0}+76.3, & h_{r} \leq 10 \\ 20 \log _{10} f+P_{0}+83.9, & h_{r}>10\end{cases}$

$P_{0}=40 \log _{10} d-20 \log _{10} H_{b}-10 \log _{10} H_{r}$

where $H_{b}$ is the height of the base station antenna, $H_{r}$ is the height of the mobile station antenna in meters, $d$ is the distance from base station antenna to mobile station antenna in meters, and $f$ is the frequency of transmission in megahertz $(\mathrm{MHz})$.

\section{METHODOLOGY}

The method used in collecting data is the Drive Test (DT) technique and the resources required are:

i. Vehicle to convey other mounted DT equipment around the test area at a recommended speed of $8-10$ $\mathrm{km} / \mathrm{hr}$.

ii. Laptop to serve as interface between the TEMs software and TEMs mobile station and record the measured data such as base station ID, base station antenna height, frequency of transmission, received signal level (RLx), signal quality index (SQI), signalto-interference ratio $(\mathrm{C} / \mathrm{I})$, number of calls attempt, number of calls blocked, number of dropped calls as well as handover information during the drive test.

iii. Drive Test Software (TEMS, Version 10.0.4 used) interfaces with TEMs mobile station for data measurement.

iv. TEMS Mobile Station (MS) interfaces with base station through RF for data measurement.

v. Global Positioning System (GPS) for positioning measurement during the DT.

\section{A. Calculation of Path Loss from Measured Data}

Let $E_{\min }=$ Equivalent minimum field strength, $A_{e}=$ Effective antenna aperture, $G=$ Antenna gain, $c=$ signal speed, $f=$ signal frequency, $\Phi_{\min }=$ Minimum power flux density at receiving place, $P_{L}=$ path Loss, $P_{T}=$ BTS power transmitted, $P_{R}=$ Mobile Station Power received. Then, given [3].

$E_{\text {min }}=\Phi_{\text {min }}+120+10 \log 120 \pi=\Phi_{\min }+145.8$

$\Phi_{\min }=P_{\text {smin }}-A_{e}$

Putting (29) into (28),

$E_{\text {min }}=P_{R}(d B m)-A_{e}+145.8$

But,

$P_{L}=P_{T}(d B)-P_{R}(d B)$
Putting (31) into (30) gives

$E_{\text {min }}=P_{T}(d B)-P_{L}-A_{e}+145.8$

But,

$A_{e}=G+10 \log \left(\frac{1.64\left(\frac{C}{f}\right)^{2}}{4 \pi}\right)$

Substituting (33) into (32) gives

$P_{L}(d B)=P_{T}(d B m)-G+10 \log \left(\frac{1.64\left(\frac{c}{f}\right)^{2}}{4 \pi}\right)+145.8-E_{\min }$

\section{B. Models Performance Testing Criteria}

The performance of considered models were weighed in comparison with the experimental path loss using different statistical evaluation criteria such as Sum Square Error (SSE), Average Absolute Relative Error (AARE) and NashSutcliffe efficiency coefficient (E).

\section{Sum Square Error (SSE)}

This describes the total deviation of the calculated path loss values $\left(X_{C}\right)$ from the existing path loss models output values $\left(X_{E}\right)$. Sum Square Error is given as [5].

$S S E=\sum_{i=1}^{N}\left(X_{C}-X_{E}\right)^{2}$

where $N$ is the total number of data points predicted, $X_{E}$ is the existing model values of path loss and $X_{C}$ is the calculated value of path loss. The model with the lowest SSE is considered to be the most relevant model to the study area.

\section{Average Absolute Relative Error (AARE)}

This is the average of the relative errors in the prediction of a particular variable and it is expressed as a percentage. Lower values of average absolute relative error (AARE) indicate better model performance. It can be computed as follows [5].

$A A R E=\frac{1}{N} \sum_{i=1}^{N}\left|\frac{X_{C}-X_{E}}{X_{E}}\right| X 100$

\section{E. Nash-Sutcliffe Efficiency Coefficient (E)}

The Nash-Sutcliffe efficiency coefficient is used to describe the accuracy of model outputs in relation to calculated data. A value of $E$ equal to 1 depicts a perfect match between calculated path loss model and existing path loss model outputs; therefore, the closer the model efficiency is to unity $(+1)$ the more accurate the model [5]. $E$ is computed as follows:

$$
E=1-\frac{\sum\left(X_{C}-X_{E}\right)^{2}}{\sum\left(X_{E}-\overline{X_{E}}\right)^{2}}
$$

where $\overline{X_{E}}$ is the average value of the path loss given by a particular existing model. 


\section{RESULTS AND DISCUSSION}

The field strength data collected during the drive test were converted into path loss and were subjected to statistical performance evaluation criteria. A path loss prediction model was therefore developed. Results are as presented Fig. 1 to 6

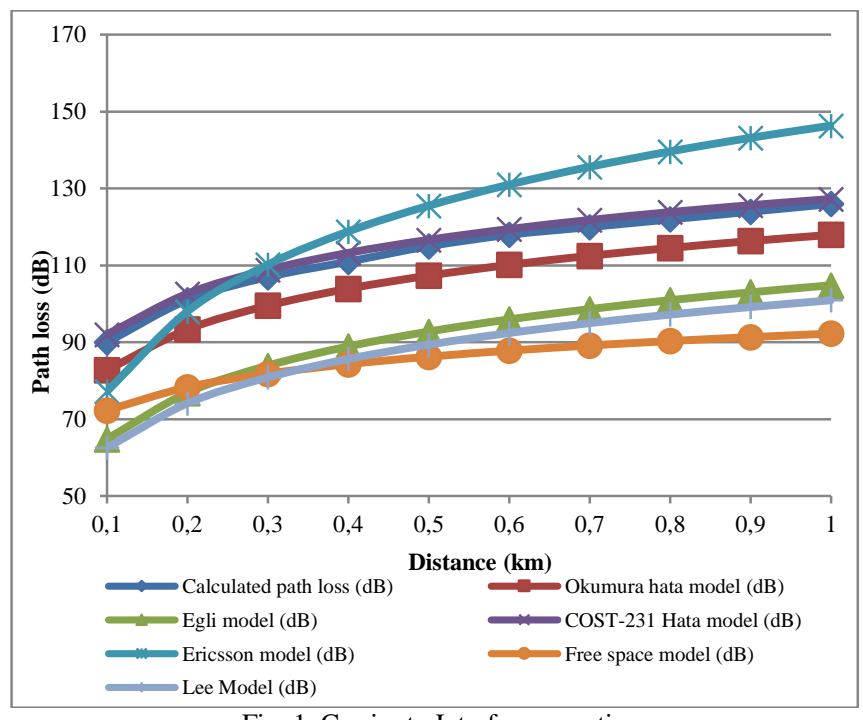

Fig. 1. Carrier to Interference ratio

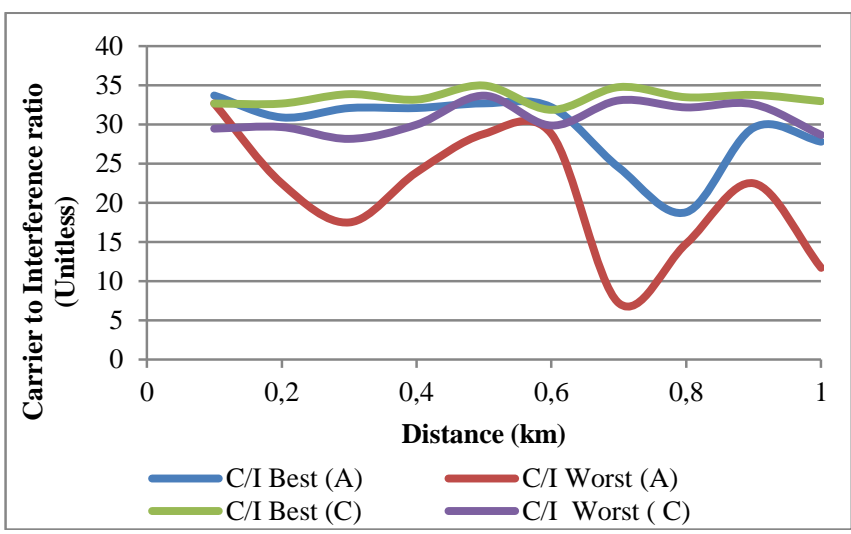

Fig. 2. Plots of the values for experimental and considered path loss models over distance

From the graph, the equation to fit the graphs is

$y=1.0124 x-2.9287$

where, $y$ is the required modified path loss and $x$ is COST 231 Hata model for path loss.

However, the regression coefficient, $R^{2}$ of the graphs is calculated to be $R^{2}=0.9995$. This indicates a good relationship between the graphs because the closer the regression ratio to unity the better.

Substituting (12), that is, COST 123 Hata path loss model for $x$ in the curve fitting equation $((38))$ and simplify gives a modified path loss prediction model for mobile communication for the studied area as

$P_{L C M M}=44.58+34.32 \log _{10} f-14.01 \log _{10} H_{b}-1.01 a H_{m}+$

$\left(45.46-6.63 \log _{10} H_{b}\right) \log _{10} d-1.01 C_{m}$

where $P_{\text {Lcmm }}$ is the modified path loss prediction model for Osogbo, Nigeria. $d$ the is distance between transmitting and receiving antennas $(\mathrm{km}), f$ is frequency of transmission
$(\mathrm{MHz}), H_{b}$ is transmitter antenna height $(\mathrm{m}), \mathrm{aHm}$ is antenna height correction factor The Parameter $C_{m}$ has different values for different environments. It is given as $0 \mathrm{~dB}$ for rural as well as suburban and $3 \mathrm{~dB}$ for urban areas.

The parameter $\mathrm{aH}_{\mathrm{m}}$ (mobile antenna height correction factor) is defined in urban areas as

$a H_{m}=3.20 \log _{10}\left(11.75 H_{r}\right)^{2}-4.81$

$H_{r}$ is the receiver antenna height in metres. Its coverage is for frequencies between $1500 \mathrm{MHz}$ and $2000 \mathrm{MHz}$, mobile station antenna height between $1 \mathrm{~m}$ and $10 \mathrm{~m}$ and base station antenna height between $30 \mathrm{~m}$ and $200 \mathrm{~m}$.

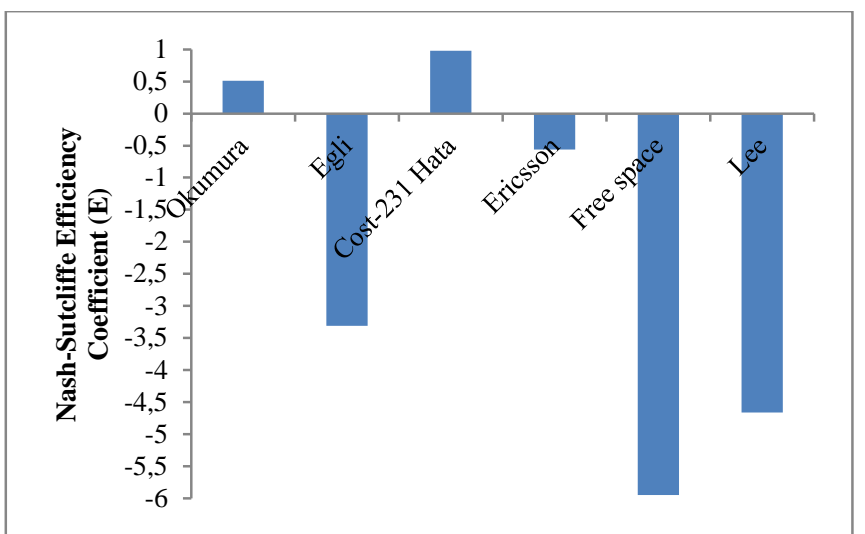

Fig. 3. SSE for the considered models and experimental path loss

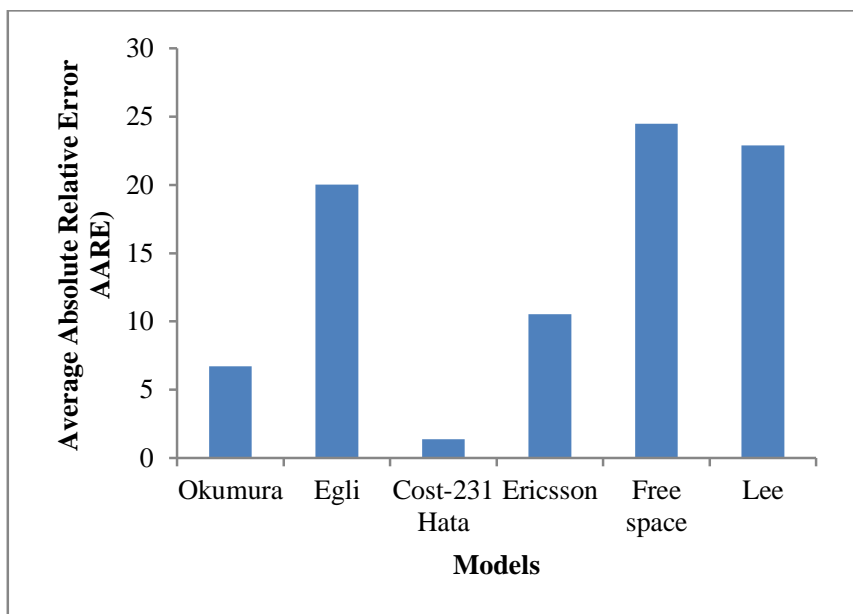

Fig. 4. AARE for the considered models and experimental path loss

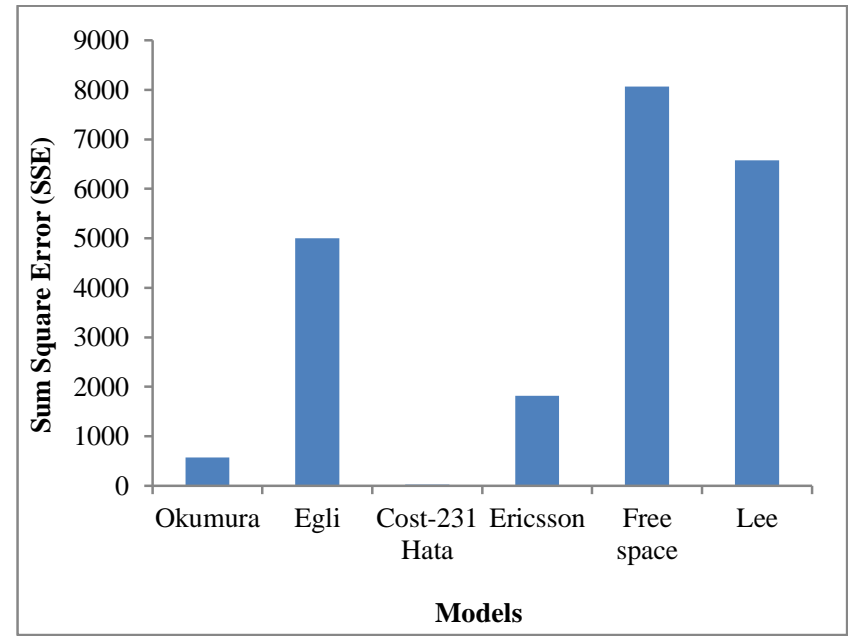

Fig. 5. E for the considered models and experimental path loss 


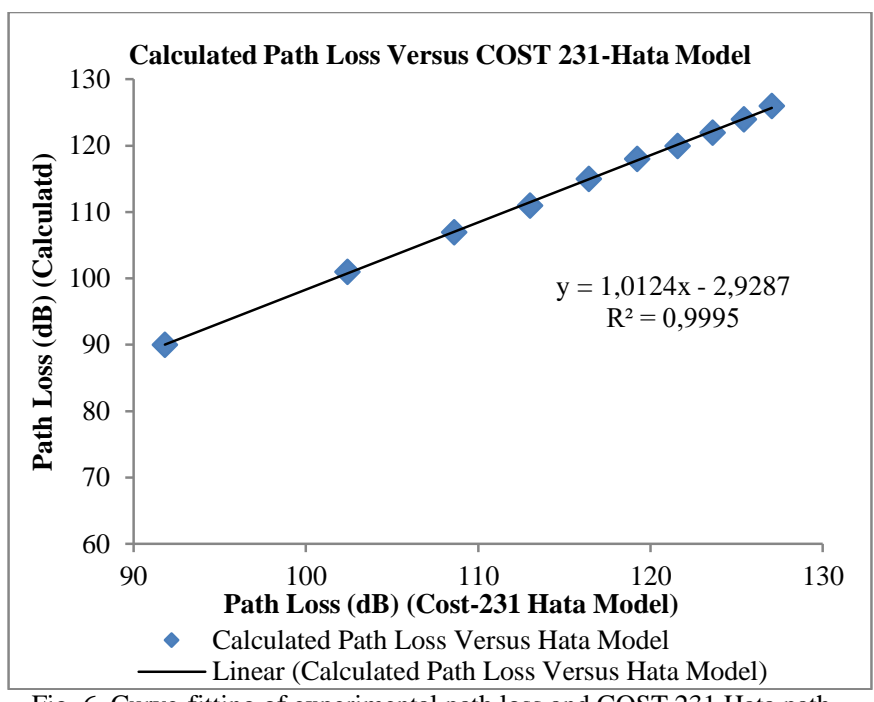

Fig. 6. Curve-fitting of experimental path loss and COST 231 Hata path loss

\section{CONCLUSION AND RECOMMENDATION}

Propagation path loss prediction model has been developed for the study area using drive test technique in conjunction with six existing models. The model indeed works very fine because there exists a high degree of correlation between its predicted path loss and experimental values when the model was verified. The method is therefore recommended because it is less tedious and less expensive compared to deterministic method which requires detailed and accurate description of all objects in the propagation space, and more expensive in computational effort. The model produces relatively accurate results. The model is extensively useful and highly recommended for conducting feasibility studies for signal prediction, coverage optimization and interference analysis during the initial phase of network planning in the study area and other areas with similar environmental and propagation characteristics.

\section{APPENDIX}

PATH LOSS VALUES FOR EXPERIMENTAL AND SELECTED MODELS

\begin{tabular}{|c|c|c|c|c|c|c|c|}
\hline $\begin{array}{l}\text { Dist } \\
\text { ance } \\
(\mathrm{km})\end{array}$ & $\begin{array}{c}\text { Experi } \\
\text { mental } \\
\text { path loss } \\
(\mathrm{dB})\end{array}$ & $\begin{array}{l}\text { Okumur } \\
\text { a hata } \\
\text { model } \\
(\mathrm{dB})\end{array}$ & $\begin{array}{r}\text { Egli } \\
\text { model } \\
(\mathrm{dB})\end{array}$ & $\begin{array}{c}\text { COST } \\
-231 \\
\text { Hata } \\
\text { model } \\
(\mathrm{dB})\end{array}$ & $\begin{array}{c}\text { Eric } \\
\text { sson } \\
\text { mode } \\
1(\mathrm{~dB})\end{array}$ & $\begin{array}{c}\text { Free } \\
\text { space } \\
\text { model } \\
(\mathrm{dB})\end{array}$ & $\begin{array}{c}\text { Lee } \\
\text { Mode } \\
1(\mathrm{~dB})\end{array}$ \\
\hline \multirow{2}{*}{0.1} & \multirow{2}{*}{90} & \multirow{2}{*}{82.7500} & 64.83 & 92.01 & 77. & 72.2 & 62.58 \\
\hline & & & 00 & 48 & 2114 & 834 & 28 \\
\hline \multirow{2}{*}{0.2} & \multirow{2}{*}{101} & \multirow{2}{*}{93.3537} & 76.87 & 102.6 & 98. & 78.3 & 74.14 \\
\hline & & & 12 & 185 & 0058 & 040 & 23 \\
\hline \multirow{2}{*}{0.3} & \multirow{2}{*}{107} & \multirow{2}{*}{99.5565} & 83.91 & 108.8 & 110 & 81.8 & 80.90 \\
\hline & & & 49 & 213 & .1698 & 258 & 43 \\
\hline \multirow{2}{*}{0.4} & \multirow{2}{*}{111} & 103.957 & 88.91 & 113.2 & 118 & 84.3 & 85.70 \\
\hline & & 5 & 24 & 223 & .8003 & 246 & 19 \\
\hline \multirow{2}{*}{0.5} & \multirow{2}{*}{115} & 107.371 & 92.78 & 116.6 & 125 & 86.2 & 89.42 \\
\hline & & 1 & 88 & 359 & .4946 & 628 & 32 \\
\hline \multirow{2}{*}{0.6} & \multirow{2}{*}{118} & 110.160 & 95.95 & 119.4 & 130 & 87.8 & 92.46 \\
\hline & & 3 & 61 & 250 & .9643 & 464 & 38 \\
\hline \multirow{2}{*}{0.7} & \multirow{2}{*}{120} & 112.518 & 98.63 & 121.7 & 135 & 89.1 & 95.03 \\
\hline & & 5 & 40 & 832 & .5888 & 853 & 46 \\
\hline \multirow{2}{*}{0.8} & \multirow{2}{*}{122} & 114.561 & 100.9 & 123.8 & 139 & 90.3 & 97.26 \\
\hline & & 2 & 536 & 260 & .5948 & 452 & 15 \\
\hline \multirow{2}{*}{0.9} & \multirow{2}{*}{124} & 116.363 & 102.9 & 125.6 & 143 & 91.3 & 99.22 \\
\hline & & 1 & 997 & 278 & .1283 & 682 & 57 \\
\hline \multirow{2}{*}{1.0} & \multirow{2}{*}{126} & 117.974 & 104.8 & 127.2 & 146 & 92.2 & 100.9 \\
\hline & & 9 & 300 & 396 & .2891 & 834 & 828 \\
\hline
\end{tabular}

\section{REFERENCES}

[1] Abidoye, L. K and Das, D. B, (2014). Artificial Neural Network Modelling of Two Phase Flow in Porous Media. Journal of Hydro Informatics, doi:10.2166/hydro.2014.079.

[2] Abhayawardhana V.S., Wassel I.J., Crosby D., Sellers M.P., and Brown M.G., (2005). Comparison of Empirical Propagation Path loss models for fixed wireless access systems. 61th IEEE Technology Conference, Stockholm, pp. 73-77, 2005.

[3] Chhaya Dalela., (2012). Propagation Path loss Modeling for Deployed WiMAX Network. International Journal of Emerging Technology and Advanced Engineering. Vol.2, Issue 8, pp. 172-176.

[4] Danladi T.A., Lawa A.U., and Aderinola M., (2013).Studies on Effects of Building Internal Pattern on Downlink Mobile Phone Signal Strengths and Power Loss. The International Journal of Engineering and Science (IJES). Vol.2, Issue 12, pp. 24-30.

[5] Egli J.J., (1957). Radio Propagation above $40 \mathrm{MC}$ over Irregular Terrain. Proceedings of the IRE. Vol.45, Issue 10, pp. 1383-1391.

[6] Goldsmith A., (2005). Wireless Communication. Cambridge University Press, New York.

[7] Isabona Joseph., Konyeha. C. C., Chinule. C. Bright., and Isaiah Gregory Peter., (2013). Radio Field Strength Propagation Data and Pathloss calculation Methods in UMTS Network. Advances in Physics Theories and Applications, Vol.21, 2013.

[8] Jalel Chebi., Ali K. Lawas., and Rafiigul Islam M.D., (2013). Comparison between Measured and Predicted Path Loss for Mobile Communication in Malaysia. World Applied Sciences Journal (Mathematical Applications in Engineering). Vol.21, pp.123-128.

[9] Josip Milanovic, Rimac-Drlje S., and Bejuk K., (2007). Comparison of propagation model accuracy for WiMAX on 3.5GHz. 14th IEEE International conference on electronic circuits and systems, Morocco, pp. 111-114.

[10] Mohammad Shahajahan and Abdulla Hes-Shafi A.Q.M., (2009). Analysis of Propagation Models for WiMAX at $3.5 \mathrm{GHz}$. MSc Blekinge Institute of Technology, Karlskrona, Sweden.

[11] Segun I.P., and Olasunkanmi F.O., (2014). Empirical Path Loss Models for GSM Network Deployment in Makurdi, Nigeria International Refereed Journal of Engineering and Science (IRJES). Vol.3, Issue6, pp.85-94.

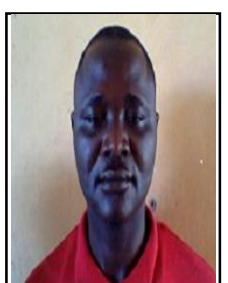

Lasisi Hammed is a lecturer and researcher in the department of Electrical and Electronics Engineering, Osun state University, Osogbo, Nigeria. He holds doctorate (Ph.D) and Master's degrees in Electrical and Electronics Engineering from University of Ilorin, Nigeria. His area of specialization is Telecommunication Engineering. He is a registered member of the Council for the Regulation of Engineering in Nigeria (COREN). He can be contacted on lashammed@yahoo.com.biography. Personal hobbies will be deleted from the biography. 